\title{
LPG inscription in mPOF for optical sensing
}

\author{
Min, Rui; Marques, Carlos; Bang, Ole; Ortega, Beatriz
}

Published in:

Micro-Structured and Specialty Optical Fibres V

Link to article, DOI:

$10.1117 / 12.2306451$

Publication date:

2018

Document Version

Publisher's PDF, also known as Version of record

Link back to DTU Orbit

Citation (APA):

Min, R., Marques, C., Bang, O., \& Ortega, B. (2018). LPG inscription in mPOF for optical sensing. In MicroStructured and Specialty Optical Fibres V (Vol. 10681). [1068108] SPIE - International Society for Optical Engineering. Proceedings of SPIE - The International Society for Optical Engineering https://doi.org/10.1117/12.2306451

\section{General rights}

Copyright and moral rights for the publications made accessible in the public portal are retained by the authors and/or other copyright owners and it is a condition of accessing publications that users recognise and abide by the legal requirements associated with these rights.

- Users may download and print one copy of any publication from the public portal for the purpose of private study or research.

- You may not further distribute the material or use it for any profit-making activity or commercial gain

- You may freely distribute the URL identifying the publication in the public portal

If you believe that this document breaches copyright please contact us providing details, and we will remove access to the work immediately and investigate your claim 


\section{LPG inscription in mPOF for optical sensing}

Rui Min, Carlos Marques, Ole Bang, Beatriz Ortega

Rui Min, Carlos Marques, Ole Bang, Beatriz Ortega, "LPG inscription in mPOF for optical sensing," Proc. SPIE 10681, Micro-Structured and Specialty Optical Fibres V, 1068108 (9 May 2018); doi: 10.1117/12.2306451

SPIE. Event: SPIE Photonics Europe, 2018, Strasbourg, France 


\title{
LPG inscription in mPOF for optical sensing
}

\author{
Rui Min*a ${ }^{*}$, Carlos Marques ${ }^{\mathrm{b}}$, Ole Bang ${ }^{\mathrm{c}}$, Beatriz Ortega ${ }^{\mathrm{a}}$ \\ ${ }^{a}$ ITEAM Research Institute, Universitat Politècnica de València, Valencia, Spain; \\ ${ }^{\mathrm{b}}$ Instituto de Telecomunicações and Physics Department \& I3N, Universidade de Aveiro, Portugal \\ ${ }^{c}$ DTU Fotonik, Department of Photonics Engineering, Technical University of Denmark
}

\begin{abstract}
We demonstrate a long period grating (LPG) inscription in microstructured polymer optical fibers (mPOFs) using a single $248 \mathrm{~nm}$ UV laser pulse of $15 \mathrm{~ns}$ duration for every inscription point using a point by point technique with total length of $25 \mathrm{~mm}$. The fabrication time indicates shortening for a single coupling point (15 ns against $42 \mathrm{~s}$ reported in literature). A grating with $20 \mathrm{~dB}$ transmission dip has been fabrication by using two UV pulses for each coupling point. The device has been fabricated in MPOF with a core that has been doped with benzyl dimethyl ketal (BDK) for photosensitivity increase. The strain and temperature responses of the fabricated gratings under different conditions have been characterized in order to assess the viability for sensing applications. Better performance was achieved with suitable post annealing process of the gratings.
\end{abstract}

Keywords: Polymer optical fibers, fiber Bragg gratings, optical sensing

\section{INTRODUCTION}

During the last two decades, long period fiber gratings (LPGs) have attracted significant attention due to their successful applications for sensing. The advantage of LPGs includes low insertion loss, ease of fabrication and low back reflection. Fabrication of LPGs in silica photonic crystal fibers is already a mature technology. A variety of fabrication techniques have been developed including irradiation using CO2 laser [1], electric arc [2], femtosecond laser [3] and UV laser [4]. Various LPGs have been explored as sensors for a variety of parameters such as strain [5], temperature [6], refractive index [7-8] and biochemical sensing [9]. The motivation for fabricating LPGs in microstructured POF (mPOF) is driven by potential sensing applications exploiting the properties of polymer optical fibers (POF) such as the small Young's modulus and large range of strain. Besides them, POF's biocompatibility offers a potential for in vivo sensing. As a recent application, an all-plastic fiber-based pressure sensor based on LPG in mPOF has been explored [10]. Only a few papers mentioned the fabrication process of LPGs in mPOF [10-14]. The first LPG was fabricated in mPOF by mechanical deformation and heating [11]. UV photo inscription of LPG in MPOF with point-by-point technique was reported in 2010 [12], where water diffusion process of the grating was investigated to report the potential sensing application as water level detectors. Hydrostatic pressure and strain sensitivity was investigated using an LPG in mPOF fabricated using transverse periodic loading combined with heating [13]. The same group fabricated LPGs based on mPOF with the cladding doped with trans-4-stilbenemethanol in order to shorten the fabrication process time, and temperature and long term stability were investigated for future sensing applications [14]. Considering the fabrication time, fiber Bragg grating inscription in silica optical fiber can be achieved in less than one minute, but the inscription time in polymer fiber is much longer. Undoped polymer fibers lead to fabrication process longer than one hour, although one fast grating inscription using 1 pulse (15 ns) emitted by a high power $248 \mathrm{~nm} \mathrm{KrF}$ laser was recently reported using benzyl dimethyl ketal (BDK) doped fiber [15], which is suitable for grating irradiation during the fiber drawing process.

In this paper, we present LPG fabrication on PMMA mPOF with BDK doped core by using point by point technology, and temperature and strain sensitivity is investigated for future optical sensing applications.

\section{LONG PERIOD GRATING FABRICATION}

A PMMA mPOF with 3 rings of holes and a BDK doped core was used to inscribe LPGs. The three ring cladding microstructure has a hole-to-pitch ratio of 0.47 with an average hole diameter of $1.74 \mathrm{um}$ and an average pitch of 3.70

Micro-Structured and Specialty Optical Fibres V, edited by Kyriacos Kalli, Alexis Mendez, Christian-Alexander Bunge, Proc. of SPIE Vol. 10681, 1068108 · C 2018 SPIE CCC code: $0277-786 \mathrm{X} / 18 / \$ 18 \cdot$ doi: $10.1117 / 12.2306451$ 
um [16]. A cross-section image of the fiber is shown in the inset of Fig. 1. The fiber was annealed for 24 hours at 70 degrees prior to be used in order to release the stress in the fiber that was induced during the drawing process. After cleaving it with a special room temperature cleaver [18] and polishing it with sand paper to get a high quality end face, the fiber was connectorized and held onto the fabrication setup under $0.1 \%$ strain, as depicted in Fig. 1.

A Coherent Bragg Star Industrial-LN krypton fluoride (KrF) excimer laser system operating at $248 \mathrm{~nm}$ wavelength was employed for the LPG inscription. The laser pulse duration was $15 \mathrm{~ns}$ and the pulse energy was set at $2.95 \mathrm{~mJ}$. The laser beam profile was measured as a rectangular Tophat function of $6.0 \times 1.5 \mathrm{~mm}^{2}$ size and $2 \times 1 \mathrm{mrad}^{2}$ divergence. It was focused onto the fiber core by utilizing a plano-convex cylindrical lens (Newport CSX200AR.10) with focal length of 20 $\mathrm{cm}$. The translation stage was employed to shift the laser beam with a precision of $10 \mu \mathrm{m}$ and a slit was used to set the width of the beam where the point-by-point technique was employed to inscribe LPGs.

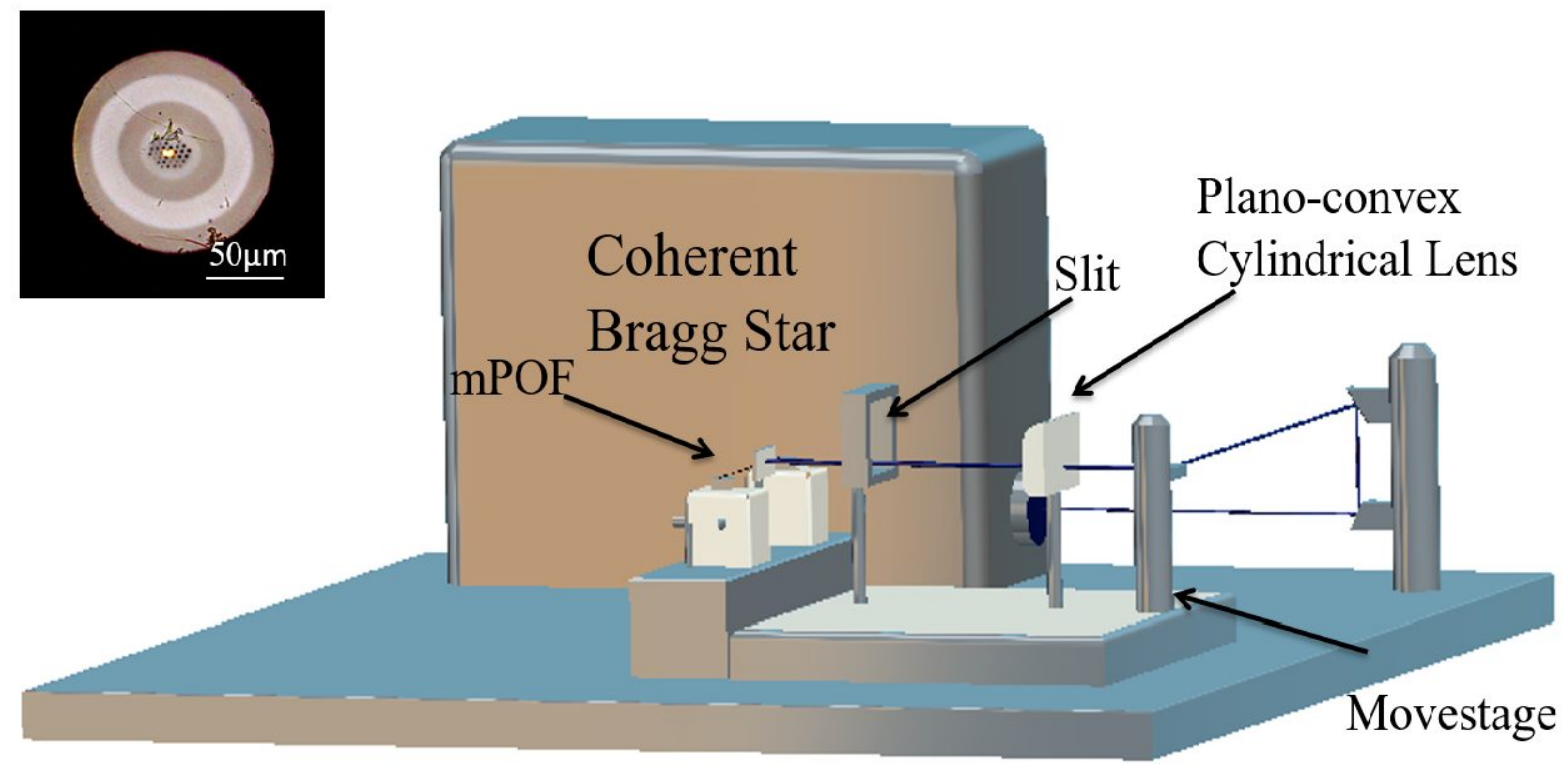

Fig. 1 Experimental setup for LPG inscription, inset: end face of mPOF

An LPG was inscribed using a single pulse for each coupling point. Fig. 2 shows the LPG transmission spectra just after fabrication when the laser is stopped and the fiber is under $0.1 \%$ strain, the grating peak is centered at $871.05 \mathrm{~nm}$ and the transmission drops $3.5 \mathrm{~dB}$. Figs. $2 \mathrm{a}$-d) show LPG transmission spectrum under different strain before post-annealing. Then, we annealed the grating at $70{ }^{\circ} \mathrm{C}$ during 24 hours, the grating showed a wavelength shift towards $869.5 \mathrm{~nm}$ and a transmission dip increase up to $5 \mathrm{~dB}$, as shown in Fig. $2 \mathrm{e}$ ), which indicates shortening of the irradiation time for a single

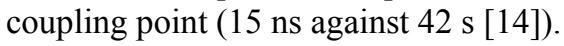

Although we tried a lot of times to inscribe gratings by using just one pulse for each coupling, not all of them were successful and lead to gratings with reasonable strength. The absorption of BDK under UV is still under research and the UV absorption is also affected by the microstructure induced diffraction [17] and it is probably too low at each coupling point. FBG can be fabricated in the same fiber by using the same laser system with a higher number of pulses [15]. In the following, two pulses were employed to obtain LPGs with better spectral response. 

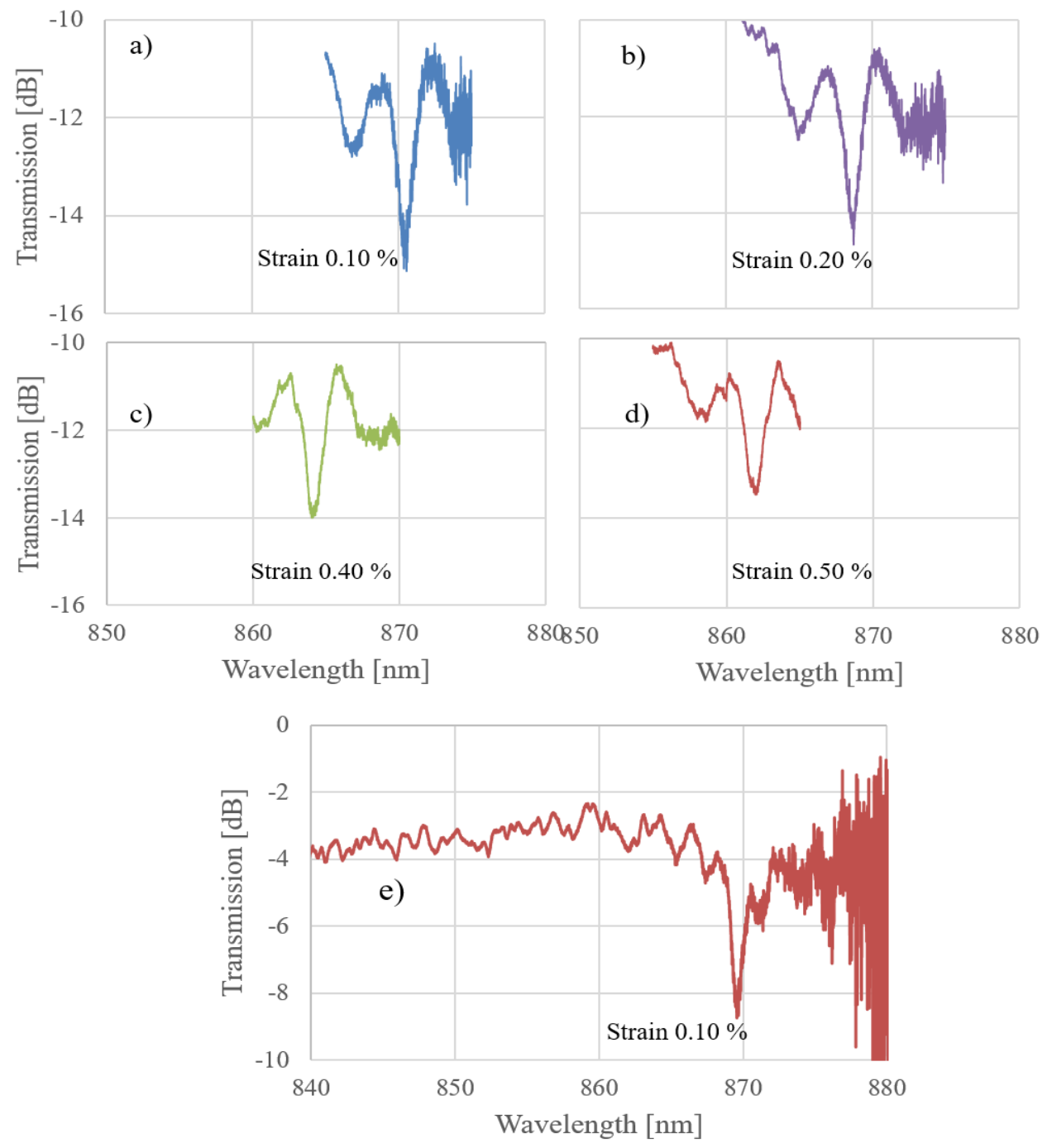

Fig. 2 Transmission response of LPG inscribed by using one pulse for each coupling point: a) Just after fabrication, b-d) LPG transmission under different strain conditions, e) After annealing at $70^{\circ} \mathrm{C}$ during 24 hours.

Figs. 3 a) and b) show the transmission depression and wavelength comparison between grating irradiation with one pulse and two pulses in each coupling. The transmission spectra of an LPG inscribed by using two pulses for each coupling, just after fabrication when different levels of strain are applied in Fig. 3 c). When the laser is stopped and the fiber is under $0.05 \%$ strain, the grating peak is centered at $869.5 \mathrm{~nm}$ and the transmission only drops $4.5 \mathrm{~dB}$, whereas the grating peak becomes more clear when it is further strained to $0.88 \%$, and the dip reaches around $-9.0 \mathrm{~dB}$ in-band transmission. Figs. 3 a) and c) indicate the performance is much better compared with one pulse per coupling point irradiated LPG. After two weeks, the grating transmission response was monitored and it showed better performance, as depicted in Fig. 3 d). Similar post growth performance was reported in FBG irradiated in annealed BDK doped PMMA fibers [15] and dye-doped PMMA polymer fibers [19], but the reason is still under research. Note that a strain of $0.1 \%$ leads to obtain $-20 \mathrm{~dB}$ in-band transmission. 

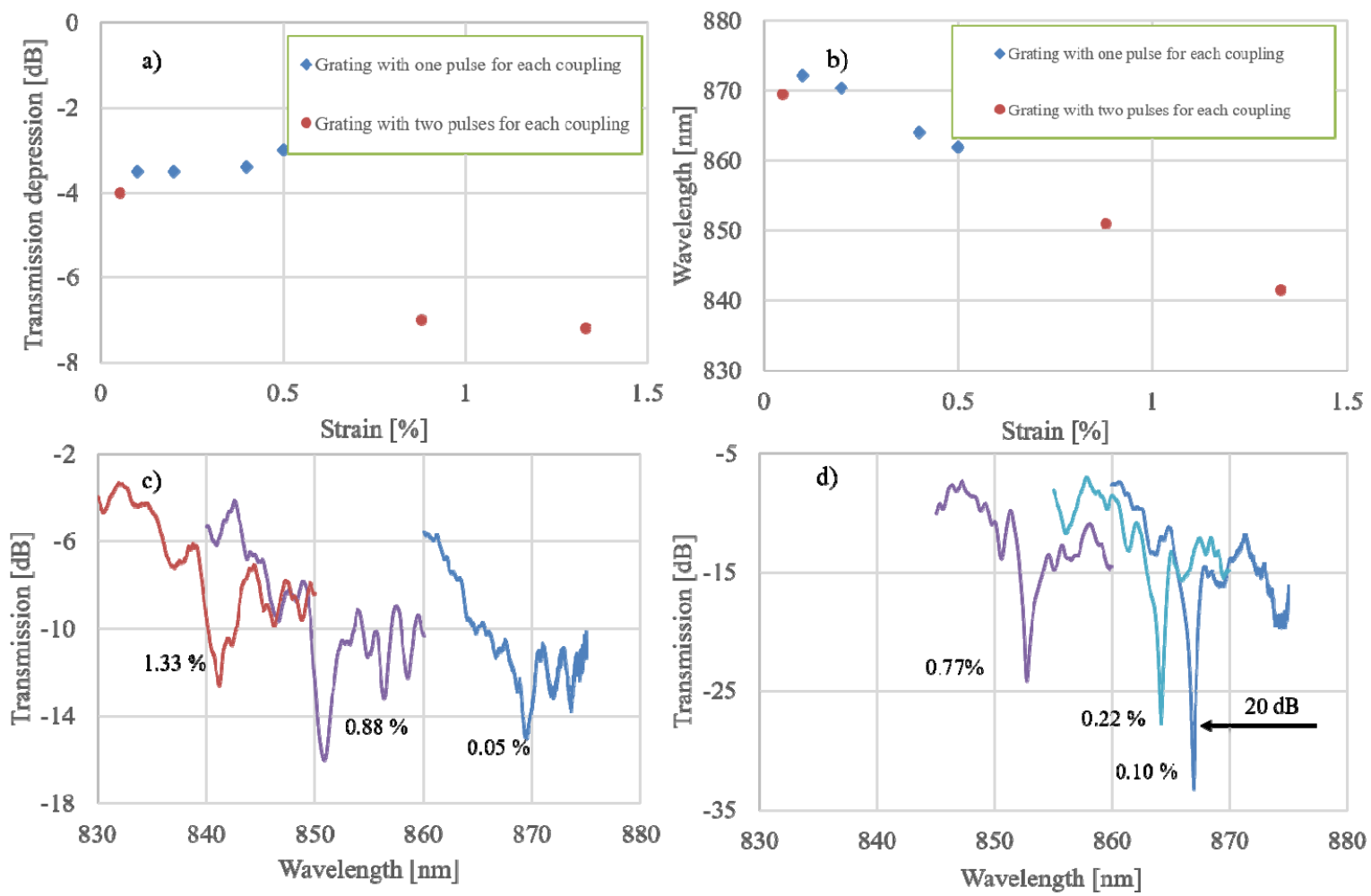

Fig. 3 a) Transmission dip vs Strain for gratings written with 1 pulse and 2 pulses for each coupling, b) Wavelength vs Strain for gratings written with 1 pulse and 2 pulses for each coupling, c) LPG inscribed by using two pulses for each coupling point (Just after fabrication), d) LPG inscribed by using two pulses for each coupling point (Two weeks after fabrication).

\section{STRAIN AND TEMPERATURE CHARACTERIZATION}

The mechanical properties of polymer material make such fibers ideal for strain sensing, so the strain response of the fibers was characterized by monitoring the position of the transmission peak when strain was applied. An $18.1 \mathrm{~cm}$ long POF section was fixed with epoxy glue on the flexure stage accessories. The flexure stage avoids sliding and strain can be easily controlled by the 3D translation stage with $20 \mu \mathrm{m}$ step. One stage was fixed and the other one was used to shift longitudinally for applying an axial strain to the fiber. Fig. 4 a) showed the strain leads to a wavelength displacement towards shorter wavelength with $-2.3 \pm 0.05 \mathrm{~nm} / \mathrm{mstrain}$, whereas $-2.25 \pm 0.05 \mathrm{~nm} / \mathrm{mstrain}$ has been measured for decreasing strain due to polymer hysteresis. Provided temperature is stabilized for each measurement, the obtained temperature sensitivity was $0.276 \pm 0.02 \mathrm{~nm} /{ }^{\circ} \mathrm{C}$, as shown in Fig. 4.b). The resonance wavelength of the grating shows a linear behavior with temperature.

We found that the grating promptly reaches stable response under strain variations, but temperature variations need long time to be stabilized. As depicted in Fig. $4 \mathrm{c}$ ), when the temperature is changed from $27^{\circ} \mathrm{C}$ to $32{ }^{\circ} \mathrm{C}$, the grating needs about 1 hour to become stable and before stability is reached, the grating shifts towards blue and then towards red wavelengths. The large range shift observed when temperature is changed from $27{ }^{\circ} \mathrm{C}$ to $42{ }^{\circ} \mathrm{C}$ is probably due to the combined effect of humidity and temperature [22] since the water diffusion is a slow process. Oppositely, when the temperature is increased from $47{ }^{\circ} \mathrm{C}$ to $52{ }^{\circ} \mathrm{C}$ in Fig. $4 \mathrm{c}$ ), the grating needs less than 10 minutes to become stable and central wavelength only shifts by a small amount, similar performance was reported in [23], where the time required for wavelength stabilization is shorter at higher temperatures. 

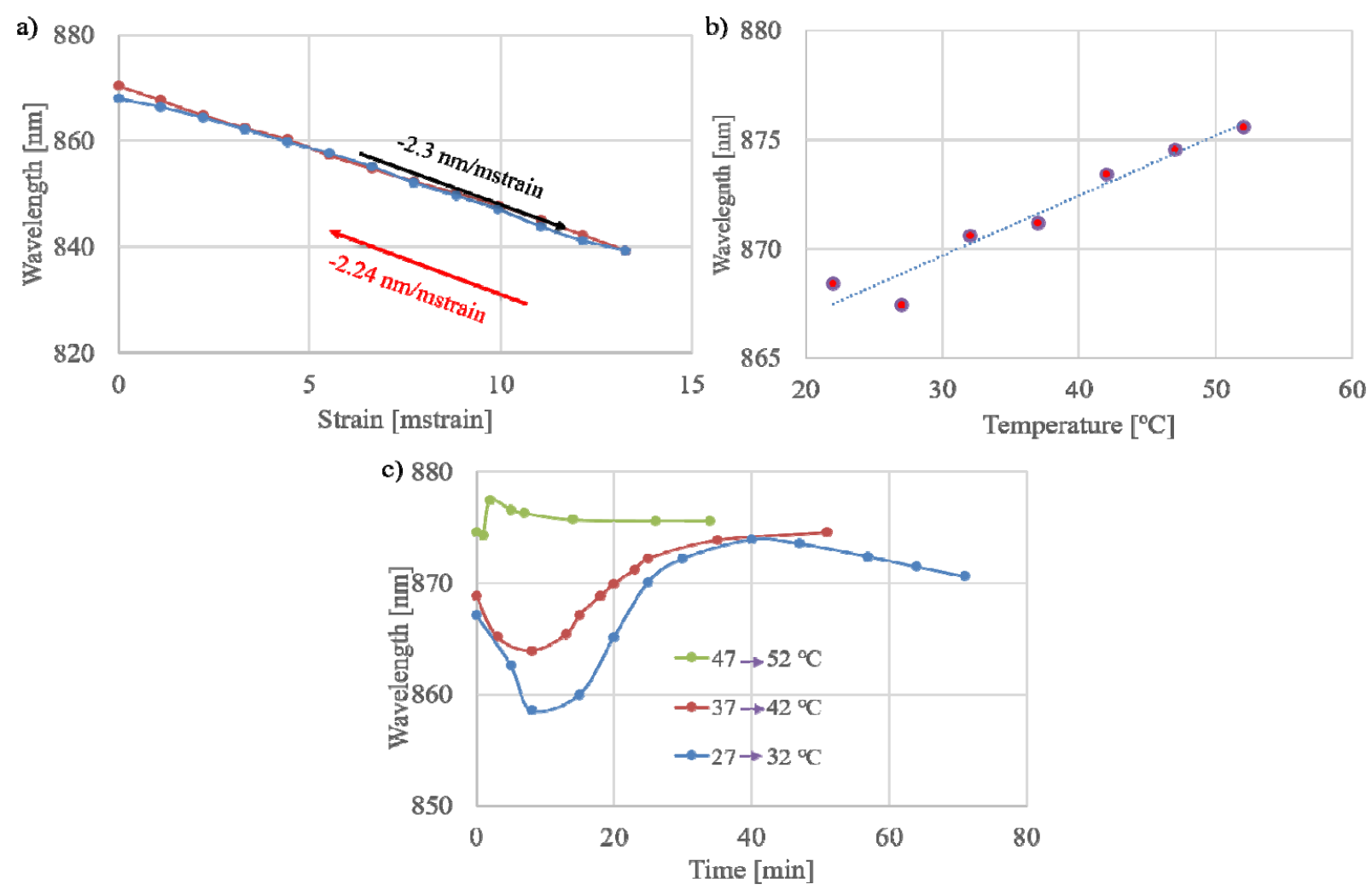

Fig. 4 a) Wavelength change induced by increasing and decreasing strain, b) Central wavelength dependence on the temperature, c) Time evolution of the LPG central wavelength for different temperature variations.

Table 1 shows the comparison of several strain and temperature sensitivities previously reported in the literature. Silica fiber LPG shows larger strain sensitivity than FBG, whereas temperature sensitivity of FBG and LPG are more or less the same. Similar comparison can be done between POF FBG and LPG. In this paper, our LPG shows larger sensitivity than mPOF LPG [13] in the table, probably due to fiber annealing for 24 hours at $70{ }^{\circ} \mathrm{C}$ as reported in [24] since the annealed fibers can produce an increase in the strain sensitivity. It also shows larger temperature sensitivity, although it needs a long time to reach a stable response, especially at temperatures below $45^{\circ} \mathrm{C}$.

Table 1. Comparison of strain and temperature sensitivity measured for LPGs and FBGs in different types of fibers.

\begin{tabular}{|c|c|c|}
\hline Type & Strain & Temperature \\
\hline Silica FBG [20] & $1.2 \mathrm{pm} / \mu \varepsilon$ & $13.7 \mathrm{pm} /{ }^{\circ} \mathrm{C}$ \\
\hline Silica LPG [6] & $-5.62 \mathrm{pm} / \mu \varepsilon$ & $11.92 \mathrm{pm} /{ }^{\circ} \mathrm{C}$ \\
\hline POF FBG [21] & $0.73 \mathrm{pm} / \mu \varepsilon$ & $-77 \mathrm{pm} /{ }^{\circ} \mathrm{C}$ \\
\hline mPOF LPG [13] & $-1.42 \mathrm{~nm} / \mathrm{mstrain}$ & Nonlinearity \\
\hline Our LPG & $-2.3 \mathrm{~nm} / \mathrm{mstrain}$ & $0.276 \mathrm{~nm} /{ }^{\circ} \mathrm{C}$ \\
\hline
\end{tabular}




\section{CONCLUSION}

To summarize, we demonstrated fast inscription of LPGs in polymer optical fibers using one $248 \mathrm{~nm}$ UV laser pulse per inscription point by using point by point technique. Therefore, the inscription time for each coupling point has been shortened compared with the best one previously reported in the literature. We demonstrated a notch depth of $20 \mathrm{~dB}$ centered at $866.9 \mathrm{~nm}$ wavelength under $0.1 \%$ strain by using two pulses per point with the same technique. The strain and thermal characterization of the LPG showed the strain and temperature sensitivity of $-2.3 \pm 0.05 \mathrm{~nm} / \mathrm{mstrain}$ and $0.276 \pm 0.02 \mathrm{~nm} /{ }^{\circ} \mathrm{C}$, respectively, which is higher than previously reported FBGs and LPGs in silica and polymer fibers, and therefore, confirm their potential to be used as active elements for fiber optic sensing.

Acknowledgments: This work was supported by Fundação para a Ciência e Tecnologia (FCT)/MEC through national funds and when applicable co-funded by FEDER - PT2020 partnership agreement under the project UID/EEA/50008/2013. It has been also supported by the Research Excellence Award Programme GVA PROMETEO 2017/103 FUTURE MICROWAVE PHOTONIC TECHNOLOGIES AND APPLICATIONS and Fundamental Research Funds for the Heilongjiang Provincial Universities (KJCXZD201703). C. A. F. Marques also acknowledges the financial support from FCT through the fellowship SFRH/BPD/109458/2015.

\section{REFERENCES}

[1] G. Kakarantzas, T. A. Birks, and P. St J. Russell. "Structural long-period gratings in photonic crystal fibers." Opt. Lett., 27(12), 1013-1015(2002).

[2] Morishita, Katsumi, and Yoshihiro Miyake. "Fabrication and resonance wavelengths of long-period gratings written in a pure-silica photonic crystal fiber by the glass structure change." J. Lightwave Technol. 22(2), 625-630(2004).

[3] Liu, Shujing, et al. "Structural long period gratings made by drilling micro-holes in photonic crystal fibers with a femtosecond infrared laser." Opt. Express 18(6), 5496-5503(2010).

[4] Eggleton, B. J., et al. "Cladding-mode-resonances in air-silica microstructure optical fibers." J. Lightwave Technol. 18(8), 1084(2000).

[5] L. Rindorf, O. Bang, "Highly sensitive refractometer with a photonic-crystal-fiber long-period grating," Opt. Lett., 33, 563-565(2008).

[6] X. Zhong, Y. Wang, J. Qu, C. Liao, S. Liu, J. Tang, Q. Wang, J. Zhao, K. .M Yang and Z. Y Li., "High-sensitivity strain sensor based on inflated long period fiber grating," Opt. Lett., 39(18), 5463-5466(2014).

[7] J. L Li, W. G Zhang, S.C Gao, P.C Peng, X.L Xue, Z.Y Bai and H. Liang, "Long-period fiber grating cascaded to an S fiber taper for simultaneous measurement of temperature and refractive index, " IEEE Photon. Technol. Lett., 25(9), 888-891(2013).

[8] J.F Ding, A.P Zhang, L.Y Shao, J.H Yan and S.L He, "Fiber-taper seeded long-period grating pair as a highly sensitive refractive-index sensor," IEEE Photon. Technol. Lett., 17(6), 1247-1249(2005).

[9] L. Rindorf, J.B. Jensen, M. Dufva, P. E. Hoiby, L.H. Pedersen, O. Bang, "Photonic crystal fiber long-period gratings for biochemical sensing, " Opt. Express. 14, 8224-8231(2006).

[10] I. L Bundalo, R. Lwin, S. Leon-Saval, A. Argyros. "All-plastic fiber-based pressure sensor," Appl. Optics, 55(4), 811-816(2016).

[11] M. P. Hiscocks, M. A. van Eijkelenborg, A. Argyros, M. C. J. Large, "Stable imprinting of long-period gratings in microstructured polymer optical fibre," Opt. Express, 14(11), 4644-4649(2006).

[12] D. Saez-Rodriguez, J. L. Cruz, I. Johnson, D. J Webb, M. C. J. Large, A. Argyros, "Water diffusion into UV inscripted long period grating in microstructured polymer fiber," IEEE Sens J., 10(7),1169-1173(2010).

[13] G. Statkiewicz-Barabach, D. Kowal, M.K. Szczurowski, P. Mergo and W. Urbanczyk, "Hydrostatic pressure and strain sensitivity of long period grating fabricated in polymer microstructured fiber, " IEEE Photon. Technol. Lett., 25, 496-499(2013).

[14] D. Kowal, G. Statkiewicz-Barabach, P. Mergo and W. Urbanczyk, "Microstructured polymer optical fiber for long period gratings fabrication using an ultraviolet laser beam, " Opt. Lett, 39(8), 2242-2245(2014).

[15] A. Pospori, C.A.F. Marques, O. Bang, D.J Webb, and P. Andre, "Polymer optical fiber Bragg grating inscription with a single UV laser pulse, " Opt. Express, 25(8), 9028-9038(2017).

[16] D. Saez-Rodriguez, K. Nielsen, H. K. Rasmussen, O. Bang and D.J. Webb, "Highly photosensitive polymethyl methacrylate microstructured polymer optical fiber with doped core," Opt. Lett, 38(19), 3769-3772(2013). 
[17] Ivan-Lazar Bundalo, Kristian Nielsen, and Ole Bang. "Angle dependent Fiber Bragg grating inscription in microstructured polymer optical fibers." Opt. Express 23, 3699-3707 (2015).

[18] D. Saez-Rodriguez, R. Min, B. Ortega, K. Nielsen and D.J. Webb, "Passive and Portable Polymer Optical Fiber Cleaver, " IEEE Photon. Technol. Lett., 28(24), 2834-2837(2016).

[19] H. B. Liu, H. Y. Liu, G.D Peng and P.L. Chu, "Novel growth behaviors of fiber Bragg gratings in polymer optical fiber under UV irradiation with low power, " IEEE Photon. Technol. Lett., 16(1), 159-161(2004).

[20] Andreas Othonos, "Fiber Bragg gratings." Review of scientific instruments 68(12), 4309-4341(1997).

[21] W. Yuan, A.Stefani, and O. Bang. "Tunable polymer fiber Bragg grating (FBG) inscription: fabrication of dualFBG temperature compensated polymer optical fiber strain sensors." IEEE Photon. Technol. Lett. 24(5), 401(2012).

[22] W. Zhang, D. J. Webb, G.D Peng, "Investigation into time response of polymer fiber Bragg grating based humidity sensors," J. Lightwave Technol., 30(8), 1090-1096(2012).

[23] W. Zhang, D. J. Webb, G.D Peng, "Enhancing the sensitivity of poly (methyl methacrylate) based optical fiber Bragg grating temperature sensors," Opt. Lett. 40, 4046-4049(2015).

[24] C. Marques, A. Pospori, G. Demirci, O. Çetinkaya, B. Gawdzik, P. Antunes, O. Bang, P. Mergo, P.S André, D. J. Webb, "Fast Bragg grating inscription in PMMA polymer optical fibres: impact of thermal pre-treatment of preforms, " Sensors, 17(4), 891 - 898, (2017). 